\title{
Autonomous Pathogen Detection System
}

R.G. Langlois, A. Wang, B. Colston, D. Masquelier, L. Jones, K.S. Venkateswaran, S. Nasarabadi, S. Brown, A. Ramponi, F.P. Milanovich

\section{January 9, 2001}

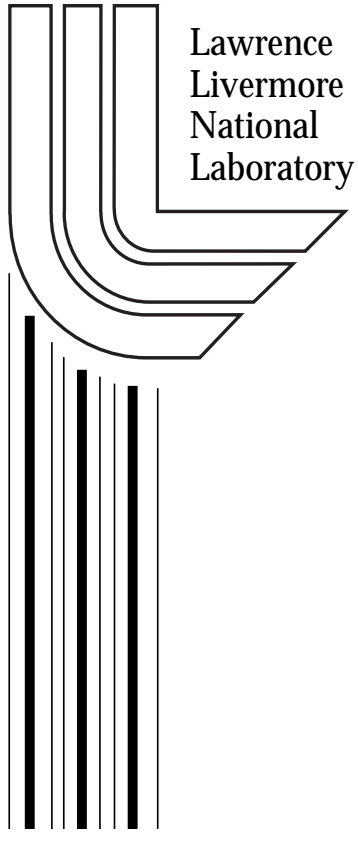




\section{DISCLAIMER}

This document was prepared as an account of work sponsored by an agency of the United States Government. Neither the United States Government nor the University of California nor any of their employees, makes any warranty, express or implied, or assumes any legal liability or responsibility for the accuracy, completeness, or usefulness of any information, apparatus, product, or process disclosed, or represents that its use would not infringe privately owned rights. Reference herein to any specific commercial product, process, or service by trade name, trademark, manufacturer, or otherwise, does not necessarily constitute or imply its endorsement, recommendation, or favoring by the United States Government or the University of California. The views and opinions of authors expressed herein do not necessarily state or reflect those of the United States Government or the University of California, and shall not be used for advertising or product endorsement purposes.

This work was performed under the auspices of the U. S. Department of Energy by the University of California, Lawrence Livermore National Laboratory under Contract No. W-7405-Eng-48.

This report has been reproduced directly from the best available copy.

Available electronically at http://www.doc.gov/bridge

Available for a processing fee to U.S. Department of Energy

And its contractors in paper from

U.S. Department of Energy

Office of Scientific and Technical Information

P.O. Box 62

Oak Ridge, TN 37831-0062

Telephone: (865) 576-8401

Facsimile: (865) 576-5728

E-mail: reports@adonis.osti.gov

Available for the sale to the public from

U.S. Department of Commerce

National Technical Information Service

5285 Port Royal Road

Springfield, VA 22161

Telephone: (800) 553-6847

Facsimile: (703) 605-6900

E-mail: orders@ntis.fedworld.gov

Online ordering: http://www.ntis.gov/ordering.htm

OR

Lawrence Livermore National Laboratory

Technical Information Department's Digital Library

http://www.llnl.gov/tid/Library.html 


\section{Autonomous Pathogen Detection System - 2001}

Richard G. Langlois, Lawrence Livermore National Laboratory (925) $422-5616$

Co-investigators: Amy Wang, Bill Colston, Don Masquelier, Les Jones, Kodumudi S. Venkateswaran, Shanavaz Nasarabadi, Steve Brown, Al Ramponi, and Fred P. Milanovich, Lawrence Livermore National Laboratory

\section{Objectives:}

The objective of this project is to design, fabricate and field-demonstrate a fully Autonomous Pathogen Detector (identifier) System (APDS). This will be accomplished by integrating a proven flow cytometer and real-time polymerase chain reaction (PCR) detector with sample collection, sample preparation and fluidics to provide a compact, autonomously operating instrument capable of simultaneously detecting multiple pathogens and/or toxins. The APDS will be designed to operate in fixed locations, where it continuously monitors air samples and automatically reports the presence of specific biological agents. The APDS will utilize both multiplex immuno and nucleic acid assays to provide 'quasi-orthogonal', multiple agent detection approaches to minimize false positives and increase the reliability of identification. Technical advancements across several fronts must first be made in order to realize the full extent of the APDS. Commercialization will be accomplished through three progressive generations of instruments.

The APDS is targeted for domestic applications in which (1) the public is at high risk of exposure to covert releases of bioagent such as in major subway systems and other transportation terminals, large office complexes, and convention centers; and (2) as part of a monitoring network of sensors integrated with command and control systems for widearea monitoring of urban areas and major gatherings (e.g., inaugurations, Olympics, etc.). In this latter application there is potential that a fully developed APDS could add value to Defense Department monitoring architectures.

The top-level goals of the program are to:

- Develop and field-demonstrate an autonomous system utilizing a single-agent flow cytometer assay,

- Add multi-agent analysis capability (multiplex detection),

- Add PCR identification capability,

- Commercialize technology,

- Partner with first-responder agencies.

\section{Recent Progress:}


Design and construction of APDS-II with multiplex immunoassay

The version 1 prototype APDS (APDS-I), consisting of an aerosol collector, sample preparation module and a flow cytometer, was completed and evaluated in a field test at the PNNL Wind Tunnel Facility. The results of this test demonstrated the feasibility of fully automated detection and identification of the simmulant, B.g., using a flow cytometric immunoassay. The components used in APDS-I, however, did not have the functionality required for extension of this approach to simultaneous identification of multiple target agents. Therefore, it was necessary to redesign all system components to construct a version 2 system (APDS-II) with fully automated multiplex immunoassay capability. A modular approach was adopted to allow each component to be developed and optimized before integration into the final system. The APDS-II modules have now been completed and integrated into a fully automated stand-alone system.

Aerosol collection and sample preparation modules

A custom two-stage aerosol collector developed at LLNL was selected and modified for the APDS-II. This collector utilizes an LLNL-designed virtual impactor pre-concentration stage in front of a commercial wetted wall cyclone collector. An on-board computer provides control of air flow rates and the size range of particles collected. A new fluidic system has been developed to provide the flexibility required for robust multiplex sample preparation. The technology of sequential injection analysis utilizes a syringe pump and multi-port valves for mixing sample with reagents, performing incubation and wash steps, and transporting samples to the flow cytometer for analysis. Computer sub-routines have been written for each fluidic operation, so that changes in assay protocol can be rapidly implemented.

\section{Multiplex detection technology}

The multiplex immunoassay technology we have chosen is bead-capture immunoassays using optically encoded beads. This technique utilizes a series of 5-micron diameter bead types, each type is dyed with a unique combination of two fluorescent dyes and is coated with a unique capture antibody. The sample is incubated with the mixture of bead types, followed by incubation with a reporter antibody containing a third fluorescent dye. We are using a Luminex flow cytometer with 3-color fluorescence detection to classify each bead type and report the presence of each target agent. At present, we have developed an assay that uses 7 bead types to monitor for 4 biological simulants, and provide 3 bead types to provide internal positive and negative controls.

System Integration 
All modules of APDS-II have been integrated into a self-contained enclosure. All fluids and reagents are contained in the instrument, so the only utilities required are AC power and a network connection for remote communication. The central computer uses a simple serial-based Labview control system to control all instrument functions. A custom software system has been developed for data acquisition, real-time data analysis, and result reporting via a graphical user interface.

Laboratory demonstration of the APDS-II system

A laboratory demonstration was designed to provide an initial evaluation of the performance of the APDS-II system. The primary objectives of this test were to demonstrate sustained autonomous operation of the instrument, and demonstrate identification of a target agent using an automated multiplex analysis. For the laboratory demonstration, the APDS-II system operated autonomously for 24 hours, continuously monitoring the air, and reporting assay results every 30 minutes. A biological simulant (MS2) was injected into the sample reservoir early in the test period, and again injected late in the test period, to evaluate the reproducibility of the assay. The results of this demonstration performed in October, 2000, showed reliable identification of the challenge agent both times with no response from assays directed toward other agent types.

\section{Future Outlook:}

We have demonstrated that the APDS system is capable of fully automated multiplex operation with bead-capture immunoassays. The primary objective for the coming year is to incorporate flow-through PCR techniques in the ADPS instrument to allow confirmation of positives obtained from the immunoassays. This will provide two complementary detection technologies to increase system reliability and minimize the possibility of false positives. The current APDS design includes space for a PCR module, so it is expected that we can continue to improve, and expand the capabilities the current platform over the coming years.

\section{Publications:}

Richard Langlois, Kodumudi Venkateswaran, Raymond Mariella and Fred Milanovich (2000), "Automated System for Microbial Identification in Aerosols," Cytometry 40 (supl. 10), p. 120. 
Kodumudi Venkateswaran, Fred Milanovich and Richard Langlois (2000), "Novel method for multiplex high-throughput flow cytometric analysis," Cytometry 40 (supl. 10), p. 40 .

Langlois, R.G., Venkateswaran, K.S., and Milanovich, F.P. (2000). Multiplex Identification of PCR Products Using Flow Cytometry.. In: Proceedings of the 2000 MASINT Biological Defense Science \& Technology Symposium.

Langlois, R.G., and Nasarabadi, S. (2000). Report on the Results of Field Tests with the LLNL Hand-held Real-time PCR Instrument (HANAA) at the IC Demo. LLNL Technical Report, UCRL- ID-137057.

Venkateswaran, K.S., Nasarabadi, S., and Langlois, R.G. (2000). Laboratory Tests of Multiplex Detection of PCR Amplicons using the Luminex 100 Flow Analyzer. LLNL Technical Report, UCRL-ID-139001.

Nasarabadi S; Milanovich F; Richards J; Belgrader P. (1999). Simultaneous detection of TaqMan probes containing Fam and Tamra reporter fluorophores. Biotechniques 27, $1116-8$.

Belgrader P; Hansford D; Kovacs GT; Venkateswaran K; Mariella R Jr; Milanovich F; Nasarabadi S; Okuzumi M; Pourahmadi F; Northrup MA. (1999) A minisonicator to rapidly disrupt bacterial spores for DNA analysis. Anal. Chem. 71, 4232-6. 


\section{APDS Annual Report- sidebars}

The use of a combination of two detection technologies will increase system reliability and reduce false positives.

The APDS-II instrument can automatically detect multiple surrogate targets.

A laboratory trial of APDS-II demonstrated automated operation for 24 hours with assay results being reported every 30 minutes.

Flow through PCR methods are being developed to provide APDS-II with two complementary detection technologies. 


\section{APDS Assay System}

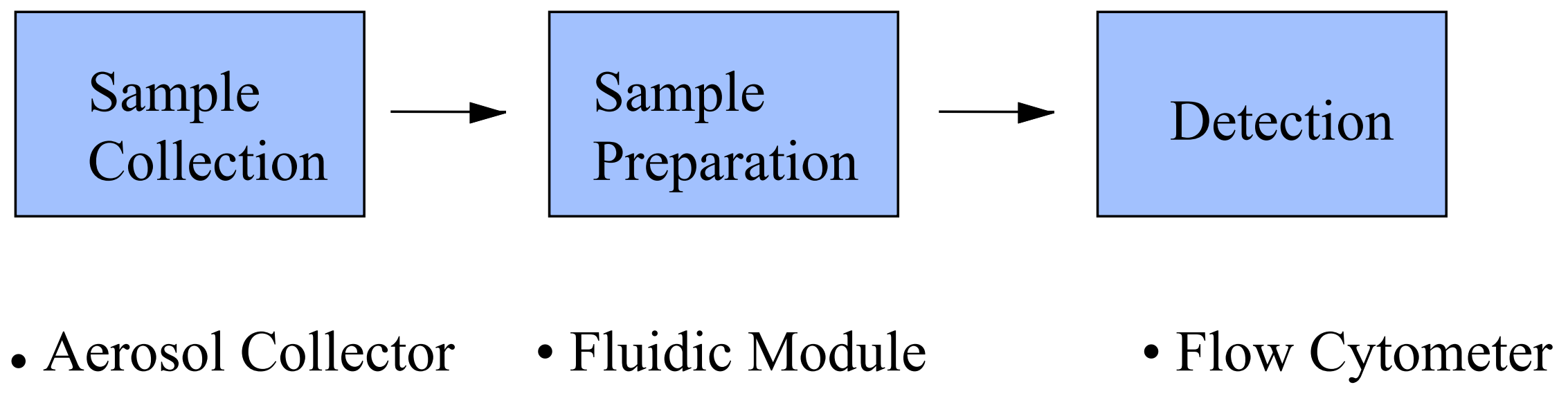




\section{APDS-II Fluidic module}

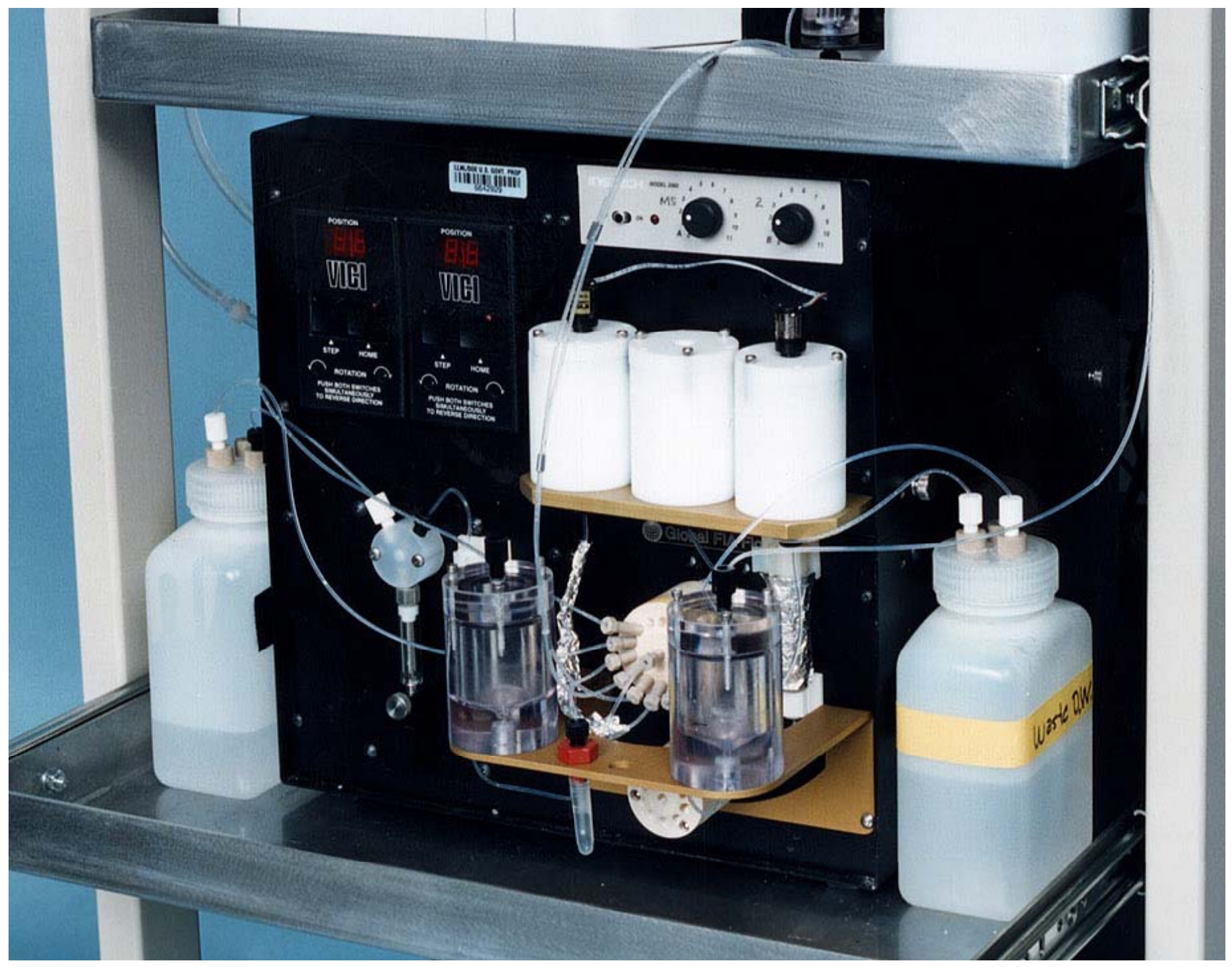


APDS-II Multiplex Monitoring System

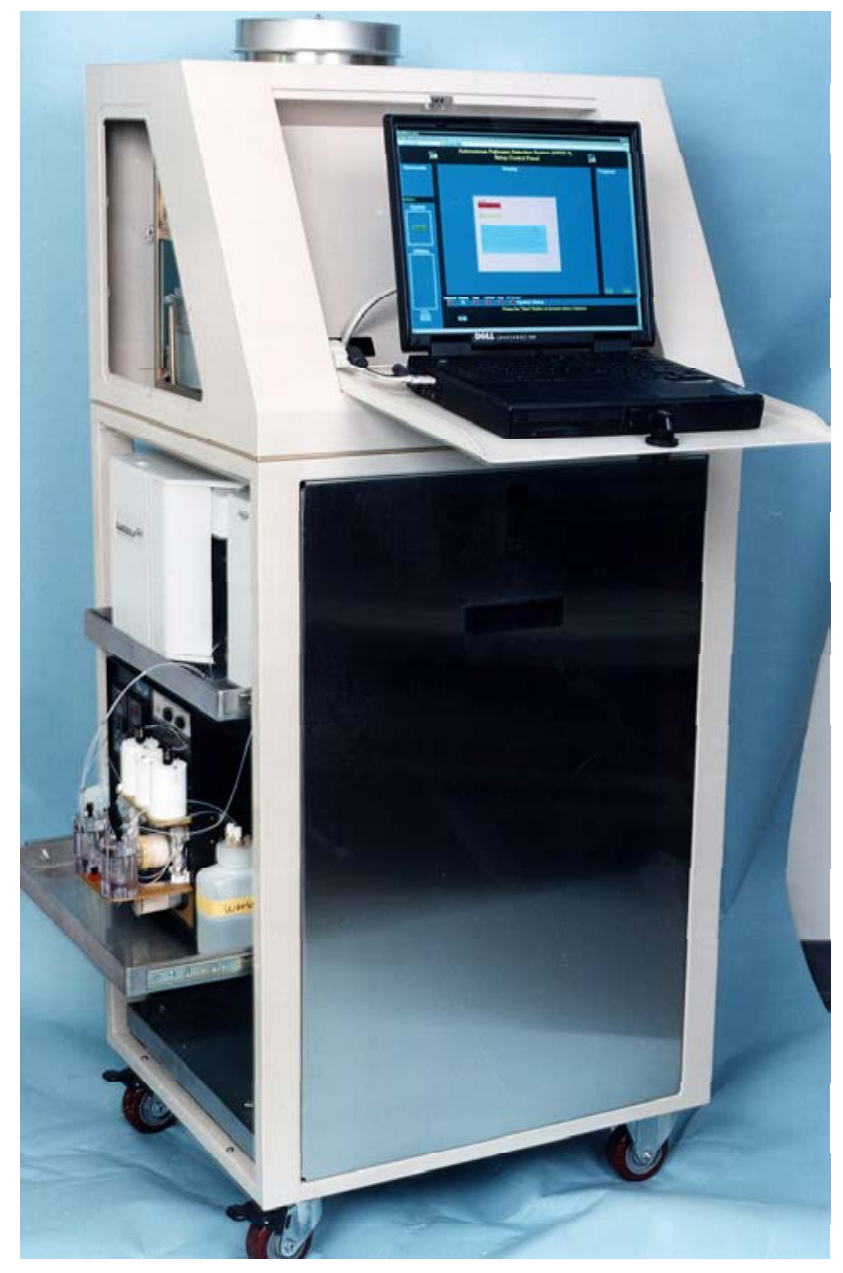




\section{Assay results from the 24 hour APDS-II test}

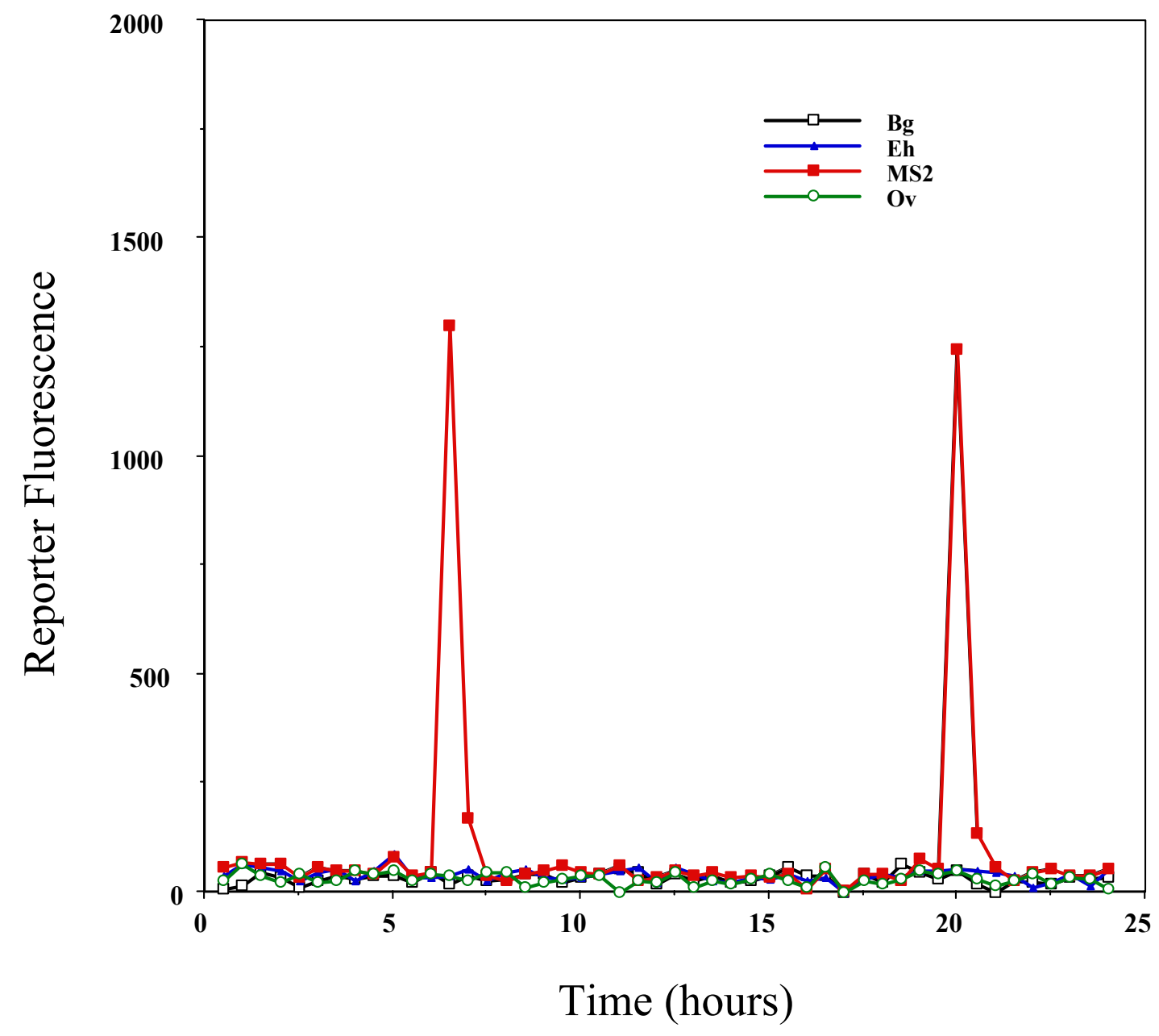

